\title{
The dichotomy of the application of a systems approach in UK healthcare the challenges and priorities for implementation.
}

Laura Pickup $^{1}$, Alexandra Lang ${ }^{2}$, Sarah Atkinson ${ }^{3}$ and Sarah Sharples ${ }^{3}$

${ }^{1}$ NIHR CLAHRC South West Peninsula (PenCLAHRC)

Medical School

University of Exeter

Exeter, EX1 2LU

${ }^{2}$ NIHR MindTech Healthcare Technology Co-operative

Institute of Mental Health

Division of Psychiatry and Applied Psychology

School of Medicine

University of Nottingham

Nottingham NG7 2TU

${ }^{3}$ Human Factors Research Group

Faculty of Engineering

University of Nottingham

Nottingham, NG7 2RD

Dr Laura Pickup (corresponding author)

Email:1.m.pickup@exeter.ac.uk,

Tel: +44 (0)1392 724474

Dr Alexandra Lang

Email:alexandra.lang@nottingham.ac.uk

Tel: +44 (0)1157486068

Dr Sarah Atkinson

Email: sarah.atkinson@ nottingham.ac.uk

Tel: +44 (0)1159514028 
Professor Sarah Sharples

Email: sarah.sharples@ nottingham.ac.uk

Tel: +44 (0)1159514196 
The dichotomy of the application of a systems approach in UK healthcare the challenges and priorities for implementation.

\section{Acknowledgements}

This work was supported by the National Patient Safety Agency (NPSA), the Scottish National Blood Transfusion Service, NHS Education for Scotland.

\section{Disclosure}

The work completed within the primary care setting was supported by NHS Education for Scotland and the National Patient Safety Agency (NPSA). The blood sampling pilot study was supported by Scottish National Blood Transfusion Service and NHS Education for Scotland.

Word count: 5931 


\title{
The dichotomy of a systems approach in UK healthcare - the challenges and priorities for implementation.
}

\author{
Abstract \\ Word count 150 \\ There is increasing demand for a systems approach within national healthcare \\ guidelines to provide a systematic and sustainable framework for improvements \\ in patient safety. Supported by this is the growing body of evidence within \\ Human Factors/Ergonomics (HFE) healthcare literature for the inclusion of this \\ approach in health service design, provision and evaluation. This paper \\ considers the current interpretation of this within UK healthcare systems and the \\ dichotomy which exists in the challenge to implement a systems approach. \\ Three case studies, from primary and secondary care, present a systems \\ approach, offering a novel perspective of primary care and blood sampling. \\ These provide practical illustrations of how HFE methods have been used in \\ collaboration with healthcare staff to understand the system for the purpose of \\ professional education, design and safety of clinical activities. The paper \\ concludes with the challenge for implementation and proposes five roles for \\ systems HFE to support patient safety.
}

\section{Practitioner Summary}

Healthcare is classified as a complex and dynamic system within this paper and as such HFE systems methods are presented as desirable to understand the system, to develop HFE tools, to deliver education and integrate HFE within healthcare systems.

Keywords: systems, patient safety, human factors, ergonomics, healthcare 


\section{Introduction}

A 'systems approach' is considered an essential feature for the integration of Human Factors/Ergonomics (HFE) principles within an organisation and to inform education and training (Dul et al. 2012). The term 'systems approach' refers to understanding the context of the human within a specific environment. This is now a well-established recommendation for the NHS within the UK to apply specifically to inform the investigation of serious adverse events and the management of patient safety (NHS England 2015a, NHS England 2015b Health Education England 2016, House of Commons 2015). However, the dichotomy remains in the challenge to implement such an approach; as the term 'systems approach' is recognised as having been misunderstood within the healthcare domain (Dekker and Leveson 2014). Outside of the HFE expert community, Healthcare HFE is currently not widely associated with an appreciation of how the design or components of a system influence the behaviour of frontline practitioners and patient experience/outcome (Waterson and Catchpole 2015). Dul et al. (2012) clearly explains the fundamental characteristics of systems HFE which adopts a hierarchical approach to system improvement; prioritising fitting the environment and tasks to the human and only if this isn't possible to select or train people to fit the environment.

This paper does not intend to debate the merits of a systems approach but rather consider the challenge for such recommendations, and the interpretation of a systems approach within healthcare service provision. Several points will be considered to explore why the challenge exists and three cases studies are offered to provide practical examples to support the interpretation of a systems approach in the context of healthcare.

Finally, the authors will consider the challenges that exist for frontline staff to engage in a systems approach and propose five key areas that could be targeted to facilitate the implementation and embed the principles of a systems approach into healthcare.

\section{Interpretation of a systems approach}

Wilson (2014) documents the misuse of the term 'systems approach', but also acknowledged the need of the HFE profession to assist in clarifying its meaning. This elucidation should provide a tangible and relevant vision of what constitutes systems HFE for the industries we work with. 
The aim of a systems approach is to improve the design of a particular system to enhance the performance, safety and wellbeing of the people that interact with it. A system can be considered as

'... a set of inter-related or coupled activities or entities (hardware, software, buildings, spaces, communities and people), with a joint purpose, links between the entities which may be of state, form, function and causation, and which changes and modifies its state and the interactions within it given circumstances and events, and which is conceptualised as existing within a boundary; it has inputs and outputs which may connect in many-to-many mappings; and with a bow to the Gestalt, the whole is usually greater (more useful, powerful, functional etc.) than the sum of the parts.' Wilson (2014 p6)

The first point to consider is how best to understand healthcare systems which imply considerable degrees of complexity (Hignett et al 2017). Vicente (1999) defines a complex system by certain characteristics of which healthcare exhibits. Specifically, these relate to the uncertainty in patient conditions, human behaviour and resources, the safety critical nature of the work which is prone to disturbances and commonly completed by multidisciplinary teams of people distributed within and between organisations. Typically the systems that frontline staff work within are a combination of several systems loosely linked which have evolved organically to meet a clinical demand (Wears and Hunte 2014). Examples include, the triangulation of care, patient transit and clinical interfacing between secondary, primary care and social services or care homes. These may differ between local areas but all share the same aims - to prioritise and attend to patients in response to their needs within the constraints of available resources. As such the complexity of many healthcare safety issues do not lend themselves to be investigated by reductionist methods but require a systems approach to investigate and support intervention design and implementation strategies (Dixon-Woods et al 2014) . To consider elements of the system in isolation, without considering the context and interactions, means there is a danger of poor decision making, poor design or recommendations for change. The use of structured systems methodologies can clarify the influential factors relevant to any design or organisational change and anticipate likely success, how it will behave once introduced and the wider ramifications within the system. However, Dixon-Woods et al (2014) acknowledges the challenge this can pose to organisations when a systems approach suggests the need for 'radical redesign and 
high level authority and resources'. This may in itself be inhibiting and without clear evidence linking the approach to safety improvement and cost effectiveness engagement with such holistic concepts may be hard to stimulate.

Secondly, how healthcare describes 'safety' governs the design of artefacts and processes presented to staff for the management of safety within an organisation.

Currently healthcare organisations and their regulators view systems as bimodal which either fail or succeed; where evidence of no harm implies safety (Hollnagel et al 2015a). This fails to consider emergence of success and failure as the norm and due to natural variability in behaviour of the system, and those within it, in response to specific contexts or competing goals (Hollnagel et al 2015b).

This can perpetuate the view held by staff on the focus of safety, investigations or interventions and how to design or query the systems they work within. This view of safety implies when everything works as it should nothing will go wrong; usually inferring if staff follow procedures the system will be safe. Presently the role and resources for safety governance in healthcare is mainly retrospective. This only considers when things don't work, rather than how things usually work and safety is achieved, in the face of multiple conflicting goals and existing hazards. Current approaches to incident reporting and analysis adopts a reductionist view of healthcare systems. This seeks to 'find and fix' components of the system that have caused harm and is completed without expertise in systems thinking or Human Factors (Peerally et al 2016). Furthermore, this 'find and fix' perspective falls short of then considering the wider implications within the system when a 'cause' is identified and addressed in isolation, in the absence of a systems approach to the development of solutions.

Thirdly the knowledge and understanding of a systems approach is limited in healthcare staff despite acknowledgements of the benefits (AHRQ 2013, Alvarado et al 2004, Carayon 2010, Norris 2011, Catchpole 2013, Gurses et al 2012, Hignett et al 2015). HFE is a scientific discipline which requires accredited HFE training, as demonstrated by the award of the royal charter in December 2014. However, this is not a criteria for NHS practitioners who deliver HFE education or interventions and may not represent a systems approach within their training. Exception to this has been the commissioning of an accredited HFE introduction course by Health Education England (Hignett et al 2017), whose remit was to improve HFE understanding of healthcare professionals and providers, the quality of which was guaranteed by the fact that the training course was delivered by qualified members of the national 
accredited body, Chartered Institute for Ergonomics and Human Factors (CIEHF). Key safety roles within the NHS e.g. Patient safety leads, governance roles do not insist on specific qualifications or education in safety or risk management either (NHS Health Education England 2016). There is also considerable variability in these roles receiving HFE education; with HFE expertise generally accessed on an ad hoc basis. Therefore what a systems approach looks like to healthcare providers can remain elusive; yet at the same time a desirable quality and field of expertise for frontline staff to apply to safety related healthcare activities. There appears to be a gap between the national goals for a systems approach in HFE to be applied; as indicated in several recent national guidance documents, and the practical capability available within NHS organisations (NHS England 2015a, NHS England 2015b Health Education England 2016). This is despite many efforts over time to promote the application of HFE generally within medical work settings and for patient safety (Straker 1989; Leape 1994; Kohn et al 1999; Hignett 2001; Flin et al 2009) and specifically encouraging a systems design approach within healthcare more widely (Leape et al 1995; Taylor Adams, Vincent \& Street 2004; Leape \& Berwick 2005; Carayon et al 2006; Carayon \& Wood 2010 NHS England 2013).

\section{The challenge for HFE and a systems approach}

Any HFE contribution must reflect the context where it is intended. So here we will consider the complexities and factors which make the need for HFE interventions and research so essential in healthcare and also present the challenges for this work.

\section{A dynamic system}

Healthcare services need to be dynamic systems which have to respond to and predict demands associated to the communities they serve. This service provision has to operate alongside the added uncertainty in how a change in Government may direct or fund healthcare systems. This creates the potential for changes in financial priorities and organisational structures every four years. Additionally, procurement processes within the NHS can have a huge effect. These can potentially constrain how frontline staff are required to accommodate systems thinking in the context of their work activities and the resulting HFE issues, some of which are outlined below. Currently, healthcare systems are not designed to 'fit the human in the system' but expect that the human element should adapt and balance organisational goals, procedures, systems, environments and equipment in the context of their everyday work. This dynamism and complexity is further compounded by the 
movement of the workforce within the organisational structure and between different healthcare systems, either geographically or temporally. Standardisation between the systems is not always evident and as such this creates additional intricacy for the workforce in regards to learning and practice.

Healthcare staff are expected to provide clinical practice and continuity of care in an everchanging landscape of their organisations. The complexity of the services and equipment with increasing utilisation of technology to support the delivery of patient care has meant a significant shift in healthcare work practices, working environments and modes of interaction within the system. Nonetheless, the goals remain the same - to avoid harm for any patient receiving healthcare interventions and to use available evidence to inform how this is achieved in the most efficient way.

\section{Technical systems}

The NHS is cited globally as a good model for healthcare (NHS Confederation 2016), there is a need to preserve the best of this institution in the context of limited resources, competing priorities and a growing and ageing population.

Cultural change may be necessary to accommodate the shift in modern systems. For example, a steady increase in the implementation and utilisation of technological solutions within the healthcare service needs to be reflected on to understand how different clinical roles benefit and consider any unexpected consequences. The change in practitioner work demands associated with many technical systems are yet to be fully evaluated in relation to workload (Magrabi et al 2015). Efforts to address this gap are growing (Cresswell \& Shiekh 2013) and will gradually contribute to a better understanding of the cultural shift in clinical practice and how existing technology influences safe and efficient health care.

The design of new healthcare technical systems often appears to be based on existing paper systems, the effectiveness and reliability of which may be unproven and relies upon how practitioners adapt these to specific clinical contexts. Technical solutions have the potential to be beneficial to the speed of information transfer and standardising the format of information, between interacting systems, organisations or teams - particularly in healthcare systems where distributed working practices are commonplace. They can promote transparency and affordance of a system to support a common understanding of patient information. However, success of a system relies upon the reliability, design and availability of technology. These 
factors determine the sequence of a practitioner's clinical actions and the reliability of selecting the right information. HFE system methods can provide a comprehensive structure to capture data on requirements of all stakeholders to ensure existing systems achieve their function. Adjustments by frontline staff in their work practices may be the norm to ensure safety and efficiency goals are balanced. Subsequently, adjustments in work practices may not reflect procedures or how managers and system designers perceive an existing system to operate. This creates a mismatch between how work is imagined and work is done (Hollnagel et al 2015a)

\section{Costs of complexity}

Healthcare requires tools which can capture and visualise the complexity of its systems to understand contributory factors, accountability and responsibilities for safety management. For example to process a single patient test sample may involve several different organisations and multiple software systems. Consequently the interactions between systems and the reliability of such systems are critical to safe and efficient diagnosis and management of a patient's health. Incompatibility, poor system design or uncontrolled changes within a poorly understood system have implications for patient safety and cost to the NHS. The estimation that harm occurs to $10 \%$ of all inpatients is commonly cited (Kohn et al. 2000) In 2014/15 the total expenditure due to litigation costs against the NHS was $£ 1,169,586,958$ (NHS Confederation 2016, NHS Litigation Authority 2014/15). Neither of these figures can be considered desirable for the wellbeing of patients and staff or for the sustainability of the NHS.

\section{Case Studies}

The three case studies described within this paper have been completed by the authors over several years, with the aim to demonstrate the breadth in application of a systems approach. The case studies represent close collaborations between healthcare and HFE professionals, providing recognition that this work has mainly been field based whilst retaining the principles of well established HFE methodologies. Such collaboration in the future is critical to develop the body of evidence for the evaluation of HFE involvement in the context of complex healthcare systems. However, to achieve this level of engagement and rigor in the HFE systems approaches adopted, consideration of the challenges within such a context is required.

HFE is described in Dul et al's 2012 statement paper as focusing on different aspects of the 
person and environment in the context of a goal orientated and purposefully designed system. The focus of the case studies illustrate three different contexts where a systems approach has not previously been applied (Singh et al 2014, Cottrell et al 2013). Case 1 considers integration of HFE into General Practitioners trainee education to enhance understanding of the 'systems approach' by frontline staff. Case 2 considers the system interactions and design of primary care healthcare settings, representing how healthcare systems can be understood and their influence on safety. Finally, case 3 investigates a safety relevant work process to understand how a systems approach can explain variability in the safety and performance of blood sampling.

The table below provide a high level overview of each case and a narrative description of methods which promote how a systems approach contributed to the output of each study. The following sections provide descriptive accounts of the outcomes and learning points for the healthcare service/ industry.

\section{Table 1 Summary of case studies}

\section{Case 1: Primary Care HFE Education}

\begin{tabular}{ll}
\hline Summary of case & A review of existing GP training programmes to understand how \\
& systems HFE was relevant to the trainee GPs in their clinical and \\
& organisational work activities. \\
& Review of professional and organisational documents from the \\
Methods applied & General Medical Council (GMC) and the Royal College of GPs \\
& (RCGP); Interviews and informal discussions with GP Trainers, GP \\
& trainees, GP Practice Managers, Practice Nurses and Administrative \\
& staff; A Work Domain Analysis (WDA) and development of an \\
& Abstraction Hierarchy (AH) \\
Application of systems & The study sought to understand the main goals, work activities and \\
approach & systems required by the trainee GP whilst training within a GP \\
& Practice. The GP setting should be viewed as a complex \\
& sociotechnical system from a care service and specialty training \\
& perspective with any future HFE-related education and training \\
& designed to reflect their role and the structure of the wider system \\
& within which they function and interact. HFE education for GP \\
trainees (and the wider GP team) should provide sufficient breadth to \\
highlight concepts and approaches that reflect the whole
\end{tabular}


sociotechnical system and its goals of delivering high quality, safe and efficient patient care, whilst protecting the wellbeing of the workforce required to achieve this. Embracing this approach can ensure a comprehensive understanding of how the context and the design of the working environment and technologies are key to influencing human behaviour and performance in the workplace

Case 2: Design for Primary Care Settings

Summary of case

Methods applied

Application of systems approach
Develop a better understanding of the relationship between the design of GP surgeries and community hospitals and patient safety incidents through a multi method approach Review of significant event audits (SEAs), analysis of a sample of Patient Safety Incident (PSI) records from the NRLS (National Reporting and Learning System), subject matter expert workshop (Architect, practice manager, Design specialists), focus groups with those in GP/community hospital roles, a stakeholder and patients group, and Failure Modes and Effects Analysis (FMEA) of specific aspects of activities in GP surgeries and community hospitals Many of the incidents and reports were attributed to the fact that the services of the GP practice or community hospital, or even of the wider healthcare system are often understood as different and separate systems, rather than interconnected sub systems of a greater whole. It was considered that understanding of the user interactions within the wider system and subsequently within the GP surgery as a sub-system would allow for design to consider all elements of the system, and consequently reduce the risks of errors/ incidents.

Case 3: Blood Sampling in Secondary Care

\begin{tabular}{ll}
\hline $\begin{array}{l}\text { Summary of case } \\
\text { Methods applied }\end{array}$ & $\begin{array}{l}\text { To understand why variability in blood sampling occurs } \\
\text { Observation, interviews, review of incident data in one year), } \\
\text { application of the Systems Engineering Initiative for Patient } \\
\text { Safety (SEIPs) model, Functional resonance Analysis Method } \\
\text { (FRAM) } \\
\text { Application of systems } \\
\text { approach }\end{array}$ \\
& $\begin{array}{l}\text { The study looked at the whole system of blood sampling from request } \\
\text { through to sample collection, identifying the functions required as well } \\
\text { as the constraints associated with the equipment, patient identification, }\end{array}$
\end{tabular}


environment. Adopting a Human Factors approach and using the FRAM model enabled better understanding of how the work is really done within the system and why variability exists in a complex healthcare environment.

\section{Case 1 Primary Care HFE Education}

This first case study considers the primary care system specifically in the context of a General Practitioner (GP) trainee, for a full description of the findings see Mckay et al 2016. NHS Scotland requested a review of their existing GP training programmes to understand how systems HFE could be relevant to the trainee GPs in their clinical and organisational work activities. There are currently twenty goals to be achieved during GP training which relate to clinical practice but also administration of a safe and financially sustainable GP practice (GMC 2013, Royal College of General Practitioners Curriculum 2010). This exploratory study reviewed professional and organisational documents from the General Medical Council (GMC) and the Royal College of GPs (RCGP). These provided the requirements, competences and good practice guidance for the trainee GP. Interviews and informal discussions were completed with GP Trainers ( $n=2,75$ mins), GP trainees $(n=3,120$ mins), GP Practice Managers ( $n=2,110$ mins), Practice Nurses ( $n=2,70$ mins) and Administrative staff ( $\mathrm{n}=3,90$ mins) to understand the main goals, work activities and systems required by the trainee GP whilst training within a GP Practice. The first stage in this work was to interpret the data gathered to define the system within which the trainee GP works and to understand the associated context and constraints. A Work Domain Analysis (WDA) specifies the purpose, values, priorities and functions of a systems (Rasmussen 1985). This approach was considered beneficial to provide a generalised representation of the GP trainee work domain; where constraints, unanticipated events and uncertainty are typical and rely on the flexibility of the staff to accommodate and maximise safety.

A WDA is the first of five phases in a Cognitive Work Analysis (CWA). Future work would be beneficial to verify the WDA and enhance the understanding of the GP system further through completion of a CWA. This would provide a generic representation of GP work activities, strategies, organisational requirements and worker competencies required to deliver a Primary care service; there appears no evidence of such an analysis within the primary care literature. This project provided a novel representation of the GP system in the 
form of an Abstraction Hierarchy (AH) which describes the system at five levels of granularity. The rule of thumb to complete an $\mathrm{AH}$, is that each level of description can be related to the one above and below to explain 'why' the system is required, 'what' the system does and 'how' this is achieved, see Figure 1 (Vicente 1999, Miller and Vicente 2001).

Figure 1 A sample of the Abstraction Hierarchy completed for an accredited GP training surgery

Through the interviews completed an iterative approach to developing the AH was adopted. This enabled clarification of previous interviews to inform the AH overall findings and a representation of the GP system to inform developments in GP training. In summary the GP trainee is expected to interact with 18 different job roles, at least 7 different technical systems and see one patient every 20 minutes (preparing themselves for every 10 minutes once qualified). The study highlighted the core functions of the trainee GP are predominantly associated with patient consultations, the interpretation of these communications and information from a number of sources e.g. physical examinations and investigations, to inform clinical decision making and management of the patient's condition and social support. These functions are constrained by time, compatibility of systems, flow of information and the support provided within the Practice and other organisations interacted with e.g. Pharmacy, Laboratories, Social Services, Secondary Care. This study highlighted the need to understand further how system interactions, information exchange and decision making is influenced by the GP's work contexts e.g. consulting rooms, remote consultations, patient's home. The output of this study provided recommendations on the core areas of HFE, figure 2. The WDA and AH provides a map of the landscape and system within which GP trainees will practice. The interactions and constraints recognised through this project have been suggested to direct the focus of any HFE education programme for GP trainees. The recommendations from this project (McKay et al 2016) will contribute to the integration of HFE education in the context of existing GP training. This will aim to support GP trainees develop skills to understand issues at different levels of the system and improve their working environment to optimise performance, safety and wellbeing. 
Insert Figure 2 HFE areas relevant to GP training

\section{Design for Primary Care Settings}

In a healthcare environment humans interact with the facility and its equipment and technology and therefore its design can have an effect on human performance (Reiling and Chernos, 2007). Research suggests that there is a link between the environment of hospitals and patient health and wellbeing and there is some evidence that the built environment can influence the healing process and have a direct impact on patient outcomes (including levels of anxiety and stress) (Douglas and Douglas, 2004). Harris et al. (2002) distinguish three relevant dimensions of the physical environment, architectural features, interior design features and ambient features. These may influence patient safety via their influence on (for example): ease of communication between patients and medical personnel; patient behaviour (e.g. whether a patient or patient's companion feels confident to point out an error that they have spotted may have occurred within the medical environment); ease and accessibility of presentation of patient information; perceived patient privacy and confidentiality (e.g. whether patient feels that they are being overheard when communicating private information) and general level of comfort and well-being of the patient whilst in the care environment. In addition, there is a need to consider the effect of building design on the systems operating within and between healthcare environments as these can have a direct effect on patient safety (e.g. where the design of areas designated for medication preparation may affect the likelihood of errors being made for example by having inadequate lighting levels). This study aimed to develop a better understanding of the relationship between the design of GP surgeries and community hospitals and patient safety incidents. A multi method approach involved focus groups with those in GP/community hospital roles, a stakeholder group and patients, analysis of NRLS data, review of Significant Event Audits (SEAs), a workshop with subject matter experts (SMEs) and Failure Modes and Effects Analysis (FMEA) of specific aspects of activities in GP surgeries and community hospitals. This work identified a conflict between the needs of different user groups, for example with access to buildings where automatic doors were recognised as a hazard for small children but without automatic doors staff may be required to assist patients who cannot easily access though, often heavy doors.

Many of the incidents and reports can be attributed to the system of the GP practice or community hospital, or even of the wider healthcare system, for example, a long queue at a 
reception desk in a GP surgery may result in a potential patient not being able to wait to make an appointment therefore not seeing a clinician and not, therefore, receiving a timely diagnosis. This could potentially also increase the pressure on receptionists (who may already be under-staffed) who are then, possibly, more likely to make an error when booking in a patient. An example was found in the NRLS data where the wrong patient was sent to the consultation room and the consultation entered into the incorrect medical records and medication was issued on the same record. Where there are examples of conflict within a system, using them to inform the design process could assist in promoting flexibility within a design or inform where further design features are required to counteract the problems and build resilience into the system. It is apparent that those involved in the design process work within constraints and parameters set by the NHS and the availability of knowledge. Consideration through a systems approach identified a lack of information available to architects with regards to how users interact in a building, the equipment they use and the practices they adopt, information which does exist is thought to be outdated and not in line with advancements in technology or equipment. There is very little feedback provided to those involved in the design process regarding the success of their design and their knowledge of incidents or experiences of those working within the building is limited.

Whilst this process highlighted elements of known and unknown interactions, the systems approach highlights the gaps in knowledge required for designing appropriately for users in the GP and community hospital environment. By taking this approach steps are made to ease design for integration by addressing long term use and issues of congruency, integration, social process and shaping (Clegg 2000) reinforcing the system improvement approach of Dul et al. (2012). This appreciation for the human and social needs and their inextricable links to the systems requirements also facilitates dialogue and feedback culture which could lead to improved communication pathways within an organisation and externally to those who are 'brought in' from outside the health service to design their premises, technology systems and artefacts.

\section{Blood Sampling in Secondary Care}

This case study took a fresh look at a long standing issue of safety in blood sampling. The 
data suggests $50 \%$ of all near misses are related to Wrong Blood In Tube incidents (WBITs) with a 77\% increase in WBIT rates between 2010 - 2014 (Bolton-Maggs et al. 2014). A blood sample is the first activity necessary to establish the compatibility of any future blood products administered to a patient (British Committee for Standards in Haematology 2012). Transfusions of incompatible blood products may cause death or serious morbidity. Despite national guidelines and local procedures concerns linked to the sampling of bloods are particularly related to patient identification and labelling of samples (Dzik et al. 2003, Gonzalez et al. 2008, Murphy and Kay 2004).

This case study is of a pilot study completed with NHS Scotland to understand why variability exists in patient identification and labelling of blood samples (Pickup et al. 2016). The aim of this work was to understand 'work as done' rather than 'perceived to be done'. This study adopted methods not previously applied to consider the context and healthcare systems relevant to blood sampling to identify factors contributing to the variability of work practices in the context: of clinical departments, working environments and organisational goals. This was a multi method study completed in four Scottish hospitals, involving observations $(\mathrm{n}=50)$, interviews $(\mathrm{n}=15,480 \mathrm{mins})$ and a review of one year's incident data. The findings were thematically analysed using the Systems Engineering Initiative for Patient Safety (SEIPS) model (Carayon et al. 2006) and variability analysed using the Functional Resonance Analysis Method -FRAM (Hollnagel 2012). FRAM is a method specifically intended to analyse complex systems and creates a model of the interactions between the functions which represented the system for blood sampling and identify where variability in performance may have the greatest impact. Adjustments made by clinical staff to accommodate specific situations or working environments are considered using the FRAM model and identify where positive or negative variability may influence an output from one or several functions. Analysis using FRAM showed why procedures may not always be followed and explained why the output of a function may influence the safety and performance of a blood sampling activity. Figure 3 presents a summary of the core functions (inner circle) and background functions (outer circle) and the factors contributing to the variability observed. The findings suggested that use of technology was core to: the reliability of patient details, requests for a blood sample and labels being available prior to blood sampling. The accessibility, location and reliability of technology or its timely repair influenced how practitioners modified their work and checks to minimise delay in obtaining a sample and manage workload associated with a high volume of patients. The working 
contexts influenced how blood sampling functions were organised to balance clinical and safety goals in the context of organisational targets.

Figure 3 Blood sampling functions and contributory factors to how work was done

Variability was discovered in the number of practitioners involved in a single blood sampling process, whilst equipment design and environmental factors. These three contributors influenced how practitioners varied work practices to mitigate the impact of time pressures, common distractions and delays.

The systems approach ensured the context was accounted for as influential to why practitioners completed blood samples as observed and reported, not previously acknowledged in improvement initiatives. This study illustrates how variability in the practitioner's work practices balanced the trade-off between efficiency and thoroughness in order to achieve the required level of performance. This work has informed the Scottish National Blood Transfusion Team's quality Improvement agenda and has been shared with SHOT to inform and consider the existing design of the transfusion process (Bolton-Maggs et al. 2014).

\section{Case study summary}

These three case studies represent examples of methods, which adopt a systems approach. The application of which have proved beneficial in understanding the interconnecting mechanisms, procedures and organisation of the 'complex whole' -of three healthcare work contexts within primary and secondary care systems. The approach and methods employed have allowed healthcare practitioners to explore the system relative to its functions and goals, suggested as the necessary approach in the analysis of complex systems (Rasmussen 1985, Vicente 1999). These examples offer practical demonstrations of how a systems approach can increase the transparency of complex systems to inform professional education, understand the constraints on system functions and goals and how the design of the system can be better understood in relation to failure and performance variability.

\section{Implementing systems HFE into healthcare}

Carayon et al (2006) identified HFE as an innovation within healthcare, and whilst progress has been made (As described earlier in this paper) there is still much to achieve with regard to 
the diffusion, dissemination, implementation and sustainable use of HFE in healthcare.

The diffusion of HFE in UK healthcare can be seen through a steady rise in publications reflecting the application and benefit of HFE within different healthcare contexts (Bowie et al 2015, Hignett et al 2011, Lang et al 2013, Morgan et al 2013).

However, HFE in UK healthcare remains opportunistic, illustrated by the case studies presented within this paper. The dissemination of HFE, the active and planned efforts to integrate HFE is still in its infancy and less well evidenced compared to other industries (Waterson et al. 2015). However, recent action suggests a degree of momentum with HFE professionals supporting the UK healthcare industry. These include a national recommendation for accredited healthcare tailored HFE education (Health Education England 2016, Hignett et al 2016) and engagement with HFE expertise for the review of incidents (Department of Health 2015). The instigation of the Healthcare Safety Investigation Board (HSIB), who intend to employ HFE expertise, promises a positive example for the integration, of HFE and a systems approach to investigations.

Successful implementation of any innovation relies upon many factors (Greenhalgh et al 2004). System readiness and the support from top management is critical. Collaboration between managers, healthcare staff, operational managers, quality improvement teams and HFE professionals is essential to ensure healthcare can embrace the knowledge from each discipline to develop safer solutions for healthcare (Hignett et al. 2015). However, the interrelationship between professionals, otherwise known as the 'soft systems' within an organisation presents its own justifiable challenges (Hollnagel et al 2015, Kirwan 2000). Inter relationships between different professionals, time pressures, organisational priorities and management motivations all require an appreciation to understand how best to ensure the effectiveness of any improvement strategy (Pannick et al. 2015). As a profession HFE still needs to seek to understand how this can be best achieved within the existing NHS landscape and integrated to augment other improvement professionals. Human resources is another factor identified by Greenhalgh et al (2004) as relevant to successful implementation. There are multiple job roles employed within healthcare organisations, each providing a different aspect of safety and care to be co-ordinated for a single patient. This presents multiple challenges for considering interactions within and between teams, medical disciplines and different medical specialities, all with their own priorities and constraints. Patient safety is the responsibility of all but co-ordinated by few who seek to maintain a balance between identifying relevant risks and managing large sets of data to ensure they meet local system 
constraints in addition to national and organisational regulations and targets. Those in safety roles may hold relatively temporary posts, $1-2$ years, and when safety is locally improved, financial savings may be achieved by the loss of some safety roles. Regular changes in staff threaten continuity in providing high quality education to implement HFE and a systems approach within an organisation's safety management strategy.

Considering the sustainability of the implementation of HFE, in such a fluid context, the authors propose the need for the integration of a systems approach into the fabric of healthcare education and safety tools. In particular strengthening five key areas:

- HFE education within professional education and organisational mandatory training;

- Prospective hazard and risk analysis through engagement between HFE professionals and frontline staff to build expertise and organisational capacity;

- Work, system and procedure evaluation ;

- Guidance to inform development, design and procurement of equipment;

- Incident reporting and investigating systems representative of complex sociotechnical systems.

The evidence and case studies highlight the application of methods which adopt a systems approach are desirable and achievable in understanding and contributing to the design of healthcare staff education, work environments and processes. However, knowledge relevant to complex systems and the engagement required suggest the dichotomy remains for the implementation of a systems approach in healthcare. The authors have drawn on their experiences to propose five areas which they believe, through design which adopts a HFE systems approach would allow a systems approach to become integrated within healthcare organisations.

\section{Conclusion}

This paper provides an overview of the current state of systems HFE integration in healthcare and offers three case studies to illustrate how a systems approach has been applied within healthcare contexts. The studies consider contributions to HFE in healthcare education, work environment and equipment design and safety processes. To tackle the identified misconceptions about systems HFE in healthcare, this contribution proffers a 'take away' message of five key areas for where future work can find value in the application of HFE systems approaches. Championing a systems approach to be applied in healthcare is not novel, however, there appears a gulf in the interpretation and practical demonstration of what that means for practitioners and those with safety roles within the NHS. 


\section{References}

Alvarado,C,J., Cao,C., Klein,G., Weinger,M,B., Patterson,E., Cook,R,I and Carayon,P 2004. Panel: The role of human factors in healthcare - 2020. Human Factors and Ergonomics Society Annual Meeting Proceedings, 48(15):1764-1767 · September 2004.

Bolton-Maggs, PHB, Poles D, Watt, A. and Thomas, D. on behalf of the Serious Hazards of Transfusion (SHOT) Steering Group. 2014. The 2013 Annual SHOT Report.

Bowie, P., Forrest,E., Price,J., Verstappen,W., Cunningham,D., Halley,L., Grant,S., Kelly,M., \& Mckay,J 2015. “Good practice statements on safe laboratory testing: A mixed methods study by the LINNEAUS collaboration on patient safety in primary care", European Journal of General Practice, 21: 19-25, DOI: 10.3109/13814788.2015.1043724

British Committee for Standards in Haematology. Guideline on the Administration of Blood Components

2012.http://www.bcshguidelines.com/documents/Admin_blood_components_bcsh_05012 010.pdf (accessed February 2nd, 2015).

Carayon,P., Schoofs Hundt, A., Karsh B-T., Gurses, A.P., Alvarado, C.J., Smith, M. and Flatley Brennan, P. 2006. "Work System design for patient safety: the SEIPS model.” Quality and Safety in Healthcare 15(1):50-58.

Carayon, P. and K. E. Wood (2010). "Patient Safety: The Role of Human Factors and Systems Engineering." Studies in health technology and informatics 153: 23-46.

Catchpole, K. 2013. "Spreading Human Factors Expertise in Healthcare: Untangling the Knots in People and Systems.” BMJ Quality and Safety. doi: 10.1136/bmjqs-2013002036.

Clegg, C., W. 2000. "Sociotechnical principles for system design." Applied Ergonomics 31(5): 463-477.

Cottrell, S., Watson, D., Eyre, T.A., et al., 2013. Interventions to reduce wrong blood in tube errors in transfusion: a systematic review. Transfus. Med. Rev. 27, 197e205.

Cresswell, K. and A. Sheikh (2013). "Organizational issues in the implementation and 
adoption of health information technology innovations: An interpretative review." International Journal of Medical Informatics 82,5: 73-86.

Douglas, C.H and Douglas, M., R. 2004. "Patient-friendly hospital environments: exploring the patients' perspective." Health Expectations 7: 61-73.

Dekker, S,W,A and Leveson,N,G. 2016. "The systems approach to medicine". BMJ Quality and Safety, 24: 7-9.

Dixon-Woods, M., Martin,G., Tarrant,C., Bion,J., Goeschel,C., Pronovost, P., Brewster, L., Shaw,L., Sutton,L., Willars,J., Ketley,D and Woodcock, T 2014. "Learning from the independent evaluation of the second phase of the Safer Clinical Systems programme". http://www.health.org.uk/publication/safer-clinical-systems-evaluation-findings accessed on 25th November 2016.

Dul, J., Bruder, R., Buckle, P., Carayon, P., Falzon, P., Marras, W,S., Wilson, J. and Van der Doelen, B. 2012. “A Strategy for Human Factors/Ergonomics: Developing the Discipline and Profession.” Ergonomics, 55(4): 377-395.

Dzik, W. H., Murphy, M. F., Andreu, G., Heddle, N., Hogman, C., Kekomaki, R., Murphy, S., Shimizu, M., Smit-Sibinga, C. T. and the Biomedical Excellence for Safer Transfusion (BEST) Working Party of the International Society for Blood Transfusion. 2003. "An international study of the performance of sample collection from patients." Vox Sanguinis 85: 40-47.

Flin, R., et al. (2009). "Human factors in patient safety: review of topics and tools." World Health 2.GMC (2013) Good Medical Practice http://www.gmcuk.org/static/documents/content/Good_medical_practice__English_0414.pdf Accessed 5th Aug 2014

Gonzalez-Porras, J. R., Graciani, I. F., Alvarez, M., Pinto, J., Conde, M. P., Nieto, M. J. and Corral, M. 2008. "Tubes for pretransfusion testing should be collected by blood bank staff and hand labelled until the implementation of new technology for improved sample labelling. Results of a prospective study." Vox Sanguinis 95: 52-56.

Greenhalgh,T., Robert,G., Macfarlane,F., Bate,P and Kyriakidou,) 2004. Diffusion of innovations in service organisations: systematic review and recommendations. The Millbank Quarterly 82 (4): 581-629. 
Gurses AP, Ozok AA, Provonost PJ. Time to accelerate integration of human factors and ergonomics in patient safety. BMJ Quality and Safety 2012 21: 347-51.

Harris, P, B., McBride, G., Ross, C. and Curtis, L. 2002. A Place to Heal: Environmental Sources of Satisfaction Among Hospital Patients. Journal of Applied Social Psychology 32 (6): 1276-1299.

Health Education England. 2016. Improving Safety through Education and Training. https://www.hee.nhs.uk/sites/default/files/documents/FULL\%20report\%20medium\%20res\% 20for\%20web.pdf (accessed on 25th April 2016)

Hignett, S. 2001. "Embedding ergonomics in hospital culture: top-down and bottom-up strategies.” Applied Ergonomics 32: 61-69.

Hignett, S. Jones, A., and Benger, J. (2011) Portable treatment technologies for urgent care. Emergency Medicine Journal, 28 (3). pp.192-196. ISSN 1472-0205 Available from: http://eprints.uwe.ac.uk/5525

Hignett, S., Leanne-Jones,E., Miller,D., Wolf,L., Modi,C., Shahzad, M.W., Buckle, P.,Banerjee, J. and Catchpole, K. 2015. "Human Factors and Ergonomics and Quality Improvement Science: Integrating Approaches for Safety in Healthcare.” BMJ Quality and Safety doi: 10.1136/bmjqs-2014-003623

Hignett,S., Lang,A., Pickup,L., Ives,C., Fray,M., McKeown,C., Tapley,S., Woodward,M \& Bowie,P 2017. "More Holes than Cheese. What prevents the delivery of effective, high quality, and safe healthcare in England?" Ergonomics, in Press. http://dx.doi.org/10.1080/00140139.2016.1245446

Hollnagel, E. 2012. FRAM: the Functional Resonance Analysis Method. Surrey: Ashgate. Hollnagel,E., Braithwaite,J and Wears,R.L 2015a. Resilient Health Care. Ashgate, Surrey. Hollnagel,E., Wears,R.L and Braithwaite,J 2015b. From Safety-I to Safety-II: A White Paper. https://www.england.nhs.uk/signuptosafety/wpcontent/uploads/sites/16/2015/10/safety-1-safety-2-whte-papr.pdf (accessed on 25th April 2016)

House of Commons' Public Administration Select Committee (PASC). Investigating clinical incidents in the NHS. Sixth Report of Session 2014-2015. 2015. 
Kirwan, B. 2000. "Soft Systems, Hard Lessons.” Applied Ergonomics 31: 663-678.

Kohn, L.T., Corrigan, J.M., Donaldson, M.S., 2000. To Err Is Human - Building A Safer Health System. National Academy Press, Washington, DC.

Lang, A.R., Martin,J.L., Sharples, S and Crowe,J.A 2013. The effect of design on the usability and real world effectiveness of medical devices: A case study with adolescent users. Applied Ergonomics, 44: 799-810

Leape, L.L. 1994. Error in medicine. The Journal of the American Medical Association, $272,1851-1857$.

Leape LL, Bates DW, Cullen DJ, Cooper J, Demonaco HJ, Gallivan T, et al. Systems analysis of adverse drug events 1995. Journal of the American Medical Association. 1995;274 (1):35-43. [PubMed]

Leape LL and Berwick DM. Five years after To Err Is Human: What have we learned? 2005. Journal of the American Medical Association. 2005;293(19):2384-2390.

Magrabi F, Liaw ST, Arachi D, Runciman,W., Coiera,E and Kidd,MR 2015. Identifying patient safety problems associated with information technology in general practice: an analysis of incident reports, BMJ Quality and Safety 2015;01-11 doi: 10.1136/bmjqs2015-004323

McKay, J., Pickup, L., Atkinson, S., McNab, D. and Bowie, P. 2016. Exploratory Human Factors Analysis of the General Practice Speciality Training and Work Environments. Education for Primary Care. doi:10.1080/14739879.2016.1181533

Miller, C.A. and Vicente, K.J. 2001. "Comparison of Display Requirements Generated via Hierarchical Task and Abstraction-Decomposition Space Analysis Techniques.’International Journal of Cognitive Ergonomics 5(3):335-355.

Morgan,L., Robertson,E., Hadi,M., Catchpole,K., Pickering,S.,New,S., Collins,G and McCulloch,P 2013. Capturing intraoperative process deviations using a direct observational approach: the glitch method. BMJ Open doi 10.1136/bmjopen-2013-003519.

Murphy, M. F. and Kay, J. D. S. 2004. "Patient identification: problems and potential solutions." Vox Sanguinis 87: 197-202.

NHS Confederation . 2016. Key statistics on the NHS. http://www.nhsconfed.org/resources/key-statistics-on-the-nhs (accessed on 1st June 2016) 
NHS England. 2015a. National Safety Standards for Invasive Procedures (NatSSIPs).

NHS England Patient Safety Domain.

https://www.england.nhs.uk/wpcontent/uploads/2015/09/natssips-safety-standards.pdf accessed on 25th April 2016

NHS England. 2015b. Serious Incident Framework - supporting learning to prevent recurrence. NHS England Patient Safety Domain. https://www.england.nhs.uk/wpcontent/uploads/2015/04/serious-incidnt-framwrk-upd.pdf accessed on 25th April 2016

NHS England. 2013. Human Factors in Healthcare - A Concordat from the National Quality Board https://www.england.nhs.uk/wp-content/uploads/2013/11/nqb-hum-factconcord.pdf (accessed on 1st June 2016)

NHS Health Education England (2016). https://www.healthcareers.nhs.uk/exploreroles/support-services/health-and-safety-officer (accessed on 1st November 2016)

NHS Litigation Authority. 2014/15. NHS Litigation Authority Report and Accounts 2014/15, Annual Review. (accessed on 30th April 2016) https://www.gov.uk/government/uploads/system/uploads/attachment_data/file/454320/NH S_LA_Annual_Report_and_Accounts_2014-15.pdf

Norris, B.J. 2011. "Systems Human Factors: how far have we come?” BMJ Quality and Safety doi:10.1136/bmjqs-2011-000476.

Pannick, S., Sevdalis, N. and Athanasiou, T. 2015. "Beyond Clinical Engagement: a Pragmatic Model for Quality Improvement Interventions, aligning Clinical and managerial Priorities.” BMJ Quality and Safety doi:10.1136/bmjqs-2015-004453

Peerally, M.F., S. Carr, J. Waring and M. Dixon-Woods. 2016. "The problem with root cause analysis”. BMJ Quality and Safety Published Online First: [23 June 2016] doi:10.1136/bmjqs-2016-005511

Pickup,L, Atkinson,A, Hollnagel,E, Bowie,P, Gray,S, Rawlinson,S, Forrester,K 2017. Blood Sampling - Two sides to the story. Applied Ergonomics, 59: 234-242. In press. http://dx.doi.org/10.1016/j.apergo.2016.08.027.

Rasmussen,J 1985. The Role of Hierarchical Knowledge Representation in Decision making and System Management. IEEE Transactions on Systems, Man, and Cybernetics, 15,2: 
234-243.

Reiling, J and Chernos, S. 2007. "Human factors in hospital safety design.” In Handbook of Human Factors and Ergonomics in Health Care and Patient Safety, edited by Carayon, P., 2007, Lawrence Erlbaum Associates, London.

Royal College of General Practitioners Curriculum (2010). Revised 14th Aug 2013. http://www.rcgp.org.uk/gp-training-and-exams/gp-curriculum-overview.aspx.

Shekelle, P.G., R.M. Wachter, P.J. Pronovost, K. Schoelles, K.M McDonald, S.M. Dy, K. Shojania et al. 2013. "Making Health Care Safer II: An Updated Critical Analysis of the Evidence for Patient Safety Practices. Comparative Effectiveness Review No. 211". AHRQ Pub. No. 13- E001-EF. Rockville, MD: Agency for Healthcare Research and Quality.

www.ahrq.gov/research/findings/evidence-based-reports/ptsafetyuptp.html .

Singh,R., Hickner,J., Mold,J and Singh,G. 2014. "Chance favours the prepared mind": Preparing minds to systematically reduce hazards in the testing process in primary care. Journal of patient safety, 10,1:20-28.

Straker, L .1989. "Developing an Ergonomics Position in the National Health Service" In Contemporary Ergonomics edited by Megaw, E., D. Taylor and Francis, London. pp355360.

Taylor-Adams, S., Vincent, C. and Street, P. 2004. "Systems analysis of clinical incidents: the London protocol." Clinical Risk 10: 211-220.

Vicente, K. J. 1999. Cognitive Work Analysis.New Jersey, Lawrence Erlbaum Associates.

Waterson, P., and Catchpole, K. 2015. "Human factors in healthcare: welcome progress, but still scratching the surface." BMJ Quality and Safety doi:10.1136/bmjqs-2015-005074.

Wears, R and Hunte, G 2014. Seeing patient safety 'Like a State'. Safety Science, 67: 50-57 http://dx.doi.org/10.1016/j.ssci.2014.02.007 .

Wilson, J. R. 2014. "Fundamentals of systems ergonomics/human factors.” Applied Ergonomics, 45:5-13. 
